Document downloaded from:

http://hdl.handle.net/10251/65373

This paper must be cited as:

Benlloch-Dualde, J.; Buendía García, F.; Lemus Zúñiga, LG.; Cano Escribá, JC.; Gutiérrez Cuba, JV.; López-Malo, A.; Palou, E. (2013). Redesigning engineering courses by introducing digital ink technology. 43rd Annual Frontiers in Education Conference (FIE 2013). IEEE. doi:10.1109/FIE.2013.6684786.

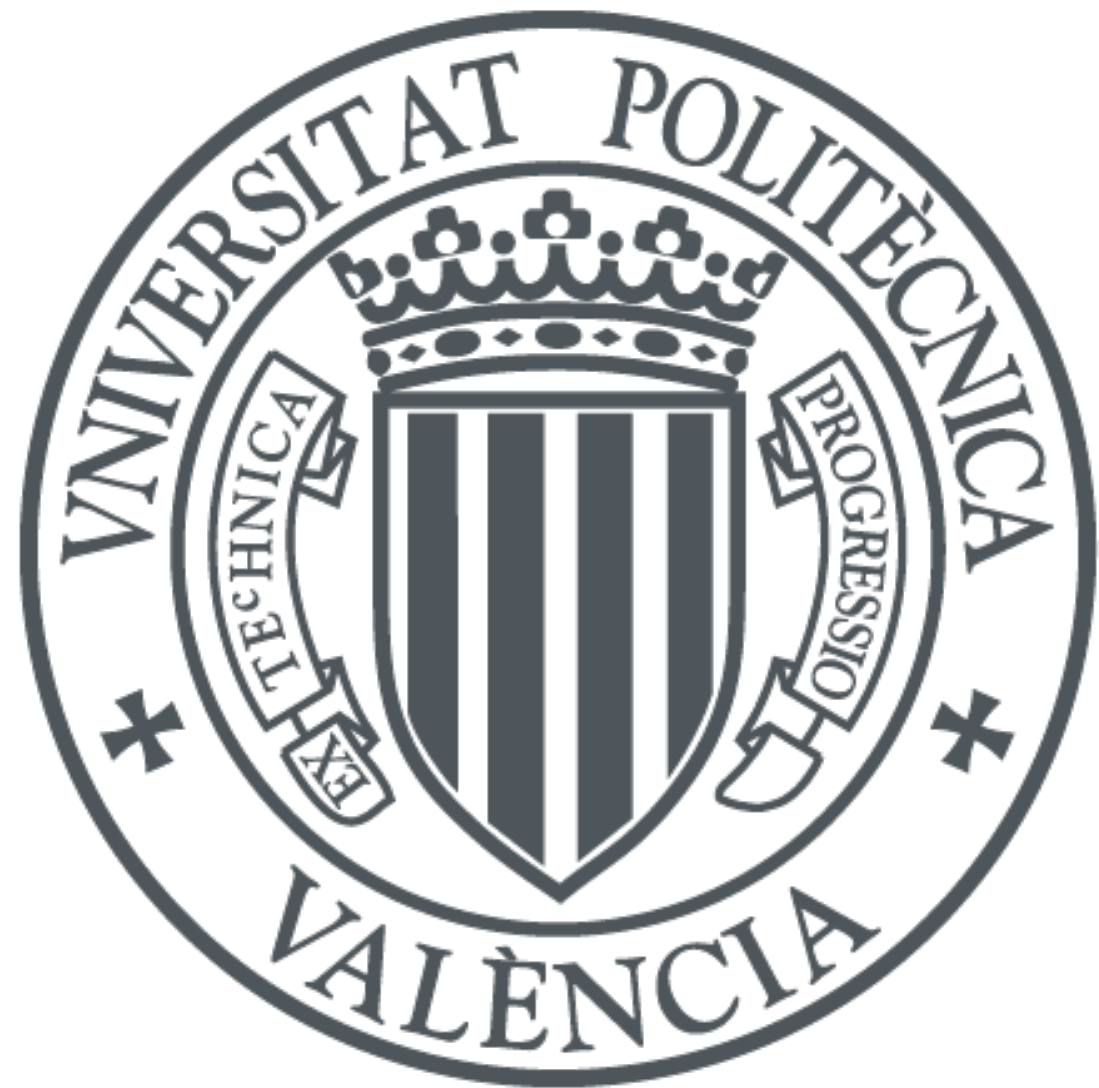

The final publication is available at

http://dx.doi.org/10.1109/FIE.2013.6684786

Copyright IEEE

Additional Information

(C) 2013 IEEE. Personal use of this material is permitted. Permission from IEEE must be obtained for all other uses, in any current or future media, including reprinting/republishing this material for advertising or promotional purposes, creating new collective works, for resale or redistribution to servers or lists, or reuse of any copyrighted component of this work in other works. 


\section{Redesigning engineering courses by introducing digital ink technology}

\author{
José-V. Benlloch-Dualde, Félix Buendía, Lenin Lemus, and \\ Juan-Carlos Cano \\ DISCA-ETSINF \\ Universitat Politècnica de València \\ Valencia, Spain \\ jbenlloc@disca.upv.es
}

\author{
J. Virginia Gutiérrez Cuba, Aurelio López-Malo, and \\ Enrique Palou \\ CECIT \\ Universidad de las Américas Puebla \\ Cholula, Mexico \\ enrique.palou@udlap.mx
}

\begin{abstract}
We applied the How People Learn framework (HPLf) in two different higher education contexts. On one hand, a first-year core course on Computer Technology, taught at the Computer Engineering Degree Program at Universitat Politècnica de València, Spain. On the other hand, two Food Chemistry related courses, taught at Universidad de las Américas Puebla, Mexico, as part of food engineering undergraduate and food science graduate programs. The goal of these works was to redesign studied courses at both universities from a lecture-based format to a "challenge-based" format by using Tablet PCs and digital ink. In order to support the studied approach, different inkenabled software tools were utilized. Class sessions were enhanced through the usage of Classroom Presenter, a penbased interaction system that supports the sharing of digital ink on slides between instructors and students. InkSurvey also allowed teachers to pose questions, receive instantly digital ink responses, and provide real-time formative feedback. Some other tools such as PDF Annotator and Ardesia helped instructors to review coursework and assignments and provide formative feedback as well. We studied our approach over the two last academic years by observing classes at both universities, obtaining selected student achievement indicators and conducting surveys with students and instructors.
\end{abstract}

Keywords-Tablet PC; Digital ink; How People Learn; Classroom Presenter; InkSurvey

\section{INTRODUCTION}

The How People Learn framework (HPLf) provides a convenient way to organize a great deal of information about the nature of competent (expert) performance and about ways to help students develop their own competence. This framework highlights a set of four overlapping lenses that are useful for designing learning environments. HPLf encourages that teachers promote student engagement both in and out of class, working in teams or individually, and what is more important, providing students with multiple feedback from different formative assessments.

Our challenge was to use HPLf to redesign different courses in two quite distinct contexts. Overall, the goal was to improve teaching and learning, creating learning environments that promote high quality interactive classrooms while formative assessment should be integrated in educational practices through the use of Tablet PCs and associated digital ink technologies.

Tablet PCs combine a standard notebook computer with a digitizing screen and a pen-like stylus device to produce a computer that allows users to easily input natural writing and/or drawing. Pedagogically, applications for the Tablet PC include lecture/presentation enhancement, problem-solving demonstrations, active learning support, guided brainstorming, reading, commenting, marking- up (providing feedback), and grading of student work. A review of the current literature supports the following advantages in using a Tablet PC: first, digital ink enables instructors to write "on the fly" during class as one would write on a chalkboard or on a transparency. This is especially meaningful for engineering and chemistry courses where examples and explanations are often mathematically and graphically intensive. Second, the freedom of marking-up significantly changes the way students and teachers interact. It facilitates bidirectional sharing of information, moving students beyond merely observing presentations to interacting with the material, the teacher, and each other. In addition, the use of Tablet PCs supports more efficient management of information. Dynamic working notes can be saved, while lecture notes with vivid annotations can become available for students' online viewing [1].

The rest of this paper is organized as follows. Section II describes the contexts where this approach was implemented. Section III outlines how the courses were redesigned and the ink-enabled software that supported these processes. Section IV summarizes the results on both contexts. Finally, section V draws some conclusions and outlines further work.

\section{CONTEXT DESCRIPTION}

As stated in the introduction, two different contexts have been used to validate our approach. On one side, at Universidad de las Americas Puebla (UDLAP), a Mexican private institution of higher education committed to first-class teaching, public service, research, and learning in a wide range of academic disciplines including business administration, the physical and social sciences, engineering, humanities, and the arts. Since 1959, the Commission on Colleges of the Southern Association of Colleges and Schools (SACS) has accredited 
UDLAP in the United States. On the other side, at Universitat Politècnica de València (UPV), a Spanish public educational institution that offers modern, flexible degrees that are designed to meet the demands of society, as well as official postgraduate programs that are subject to demanding quality control systems. It has three campus sites with a total of 36,187 students, 2,843 members of teaching and research staff, and 2,396 administrative and services staff. It is the only Spanish technological University ranked among the best in the world, according to the Academic Ranking of World Universities (compiled by Shanghai Jiao Tong University).

\section{A. UDLAP courses}

Concerning case studies, UDLAP selected 2 courses, Food Chemistry (IA-332) and Advanced Food Chemistry (IA-530) which are a junior level, 3 credit required course for food engineering and nutrition BS programs and a first- semester 3 credit required course for the food science MSc program and also an elective for the $\mathrm{PhD}$ in food science program at UDLAP, respectively. Approximately 10-25 students are enrolled in IA-332 per semester with 6-17 food engineering students and 4-8 human nutrition students, while approximately 5-10 graduate students are enrolled per semester in IA-530; these graduate students have already a BS in food engineering, food science, biology, agricultural engineering, chemistry, or pharmacy. IA-332 and IA-530 major goal is to help students think about the way a food chemist does. Thus, students are involved in answering two key questions: i) how the composition, structure and properties (especially in terms of quality and safety) of foods are affected by chemical changes the food experiences? And ii) how the understanding of key chemical and biochemical reactions can be applied to many situations encountered during formulation, processing and storage of food?

The fundamental concepts of the studied courses are, therefore, chemical and biochemical changes of food and its effect on food composition, structure, quality, and safety during formulation, processing and storage, while encouraging students think about and apply food chemistry in the same ways experienced food scientists and engineers do.

In an increasingly collaborative, mobile and globally interconnected environment, UDLAP envisions ubiquitous computing as a natural, empowering component of every teaching, learning, and research activity. UDLAP is committed not only to adopting and adapting technologies to all its scholarly endeavors, but also to playing an active role in their development [2].

\section{B. UPV course}

In contrast to UDLAP courses, Computer Technology (TCO-11544) is a first-year core subject taught during the spring term (second semester) in the Computer Engineering Degree Program that was selected at the UPV as case study. The course has 6 ECTS credits (150-180 hours). 60 hours are dedicated to face-to-face classroom work and at least 90 hours are expected as students' personal study. On average, during the last academic years, the course has dealt with 11 lecturers and more than 450 students per year, divided into 11 lecture groups and 21 lab groups. The syllabus was compiled according to national and international recommendations, the main sources being the ACM/IEEE curricula recommendations, as well as the Computer Engineering Degree Program White Paper of the National Agency for Quality Assessment and Accreditation [3].

The course is included in the field of computer engineering in ACM/IEEE computing curricula, and matches the noncomputing topic of electronics as it is focused on semiconductor devices and logic families. Computer Technology topics are not generally addressed in high school programs, so that the background of UPV students on electronics is virtually nonexistent.

\section{REDESIGNING THE COURSES}

A major aim is to help students developing the kinds of connected knowledge, skills, and attitudes that prepare them for effective lifelong learning [4][5]. This involves the need to seriously rethink not only how to help students learn about particular isolated topics but to rethink the organization of entire courses and curricula. The ability to design courses and corresponding high-quality learning environments require that we move beyond procedural strategies and models. We also need to understand the kinds of skills, attitudes, and knowledge structures that support competent performance. Thus, for the redesigning of the courses similarly as previously described [4]-[6] we "worked backwards" as suggested by Wiggins and McTighe taking into account Jenkins model as well as the HPL framework [7][8]. Especially important was knowledge of key concepts and models that provide the kinds of connected, organized knowledge structures and accompanying skills and attitudes that can set the stage for future learning [8].

Our redesigns involved a transformation of our courses from a lecture-based format to a "challenge-based" format. We use the term "challenge-based" as a general term for a variety of approaches to instruction that many have studied, these include case-based instruction, problem-based learning, learning by design, inquiry learning, anchored instruction, and so forth. There are important differences among these approaches, but important commonalities as well. We used the HPLf as a set of lenses for guiding the redesign of the lessons, development of our challenges but also the overall instruction that surrounded the challenges [5]-[7]. Our goal was to improve teaching and learning by creating high-quality learning environments that promote an interactive classroom while integrating formative assessments into classroom practices by means of Tablet PCs and associated digital ink technologies [4][9][10].

Particularly important were opportunities to make students' thinking visible and give them chances to revise. We also noted the importance of provided opportunities for "what if" thinking, given variations on the challenge and for new problems that also involved the lesson's concepts. Attempts to help people reflect on their own processes as learners (to be metacognitive) were also emphasized. We utilized several Tablet PC associated technologies to gauge student learning in real time, provide immediate feedback, and make real-time pedagogical adjustments as needed. 


\section{A. Ink-Enabled Software}

To support the described approach, different ink-enabled software tools were utilized.

Communication within the classroom was enhanced through the usage of Classroom Presenter (CP) [11], a penbased interaction system that supports the sharing of digital ink on slides between instructors and students. Instructors connect the Tablet PC to the lecture room screen to present contents, while showing their digital ink annotations in real time. CP makes possible to broadcast these contents to students' Tablet PCs, while allowing them to personalize the instructor provided materials with typed and ink annotations that each student can make, based on discussion during class (Fig. 1).

Using the work of Angelo and Cross [12], we identified Classroom Assessment Techniques (CATs) appropriate to each section of the course and then adapted them into the Tablet $\mathrm{PC} / \mathrm{CP}$ environment. Instructor utilized CATs to gauge student learning in real time and made real-time pedagogical adjustments as needed. At various points during each session, students are asked to tackle a learning activity, whether a simple exercise or a more complex problem, as in the traditional approach. In this setting, students can anonymously respond by handwriting (or typing) their solution on the Tablet PC and submitting it wirelessly to the instructor. As soon as the exercises are received, instructors can preview the student responses, select one or more to display to the class, and make annotations as they are being displayed. This option provides immediate feedback to both students and instructor about misunderstandings and enables the instructor to adjust course material in real-time based upon student answers to in-class exercises. Additionally, student responses can be saved for review after lecture by the instructor or even made available electronically to the audience. According to the instructor judgment and course design, students are asked to deliver some in-class exercises through the virtual campus platform and thus, can be used as part of the student activity score, what enables a continuous assessment.

The instructor also made use of CATs that are already features within Classroom Presenter, like the polling features (true/false as well as multiple choice questions). Students respond by clicking the corresponding answer on their Tablets. Once instructors close the poll, CP shows the corresponding results in statistical form. This strategy is also useful as a way to quickly gather formative information and in turn, to provide immediate feedback to students to help clarify misconceptions.

In order to support group work, a virtual meeting room called Vyew [14] was also employed. It is a browser-based group screen and desktop sharing platform that also offers group video chat and includes ink annotation and drawing tools. Therefore, it proved especially suited to help students to address team assignments, problem-solving or projects that usually requires everyone to have access to the common information as well as a more rich communication ways. Vyew comes with a basic free version that offers unlimited use for up to 10 people, making it more than sufficient for typical team sizes at UPV.
InkSurvey [15], a web-based tool developed specifically to allow an instructor to pose open-ended questions to students during class and receive real-time student responses was also utilized (Fig. 3). Students by means of Tablet PCs respond to these questions with their own words/sentences/paragraphs entered manually via the keyboard, or with digital ink that allows handwriting, sketches, equations, graphs, derivations, etc. Confidence level can be included if desired (as was our case). The instructor received an instantaneous compilation of web-based student responses to receive feedback in real time [2][5].

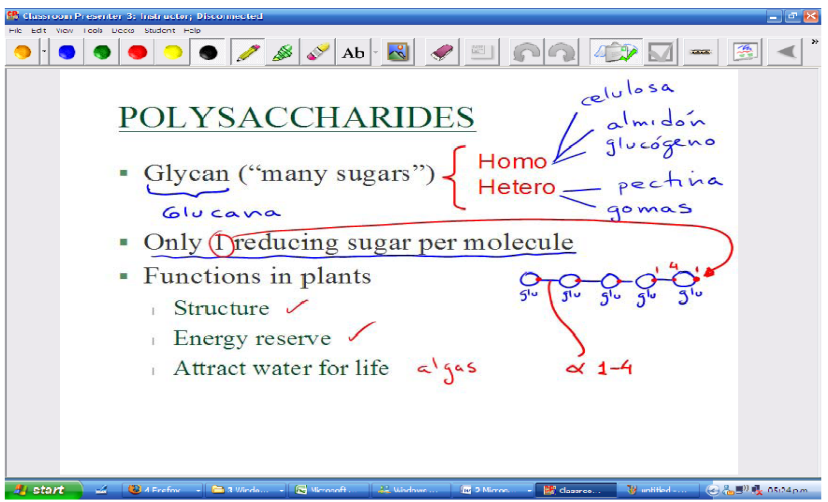

Fig. 1. Example of Classroom Presenter usage in Advanced Food Chemistry.

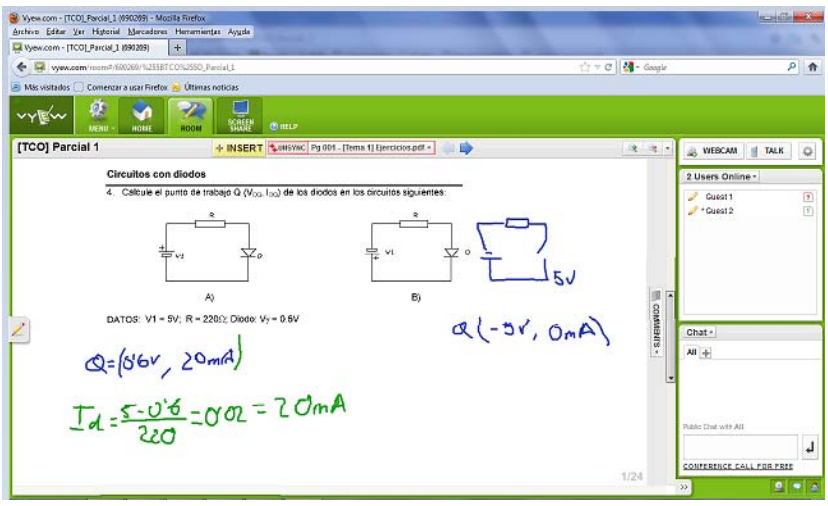

Fig. 2. Example of Vyew usage in Computer Technology.

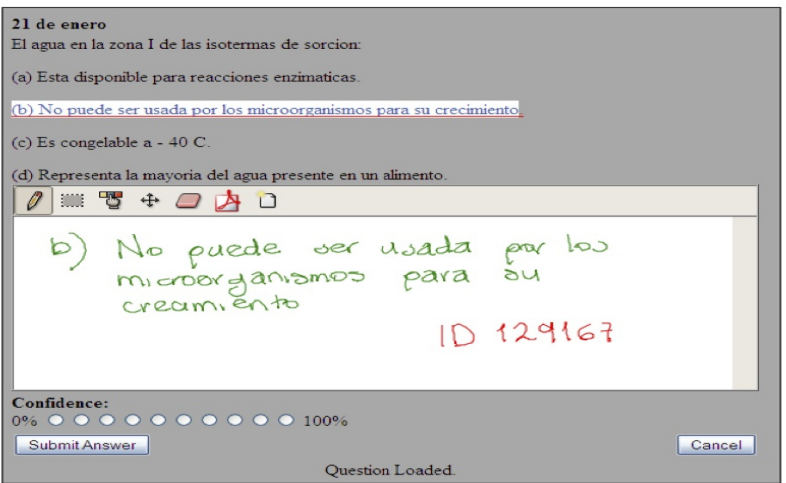

Fig. 3. Example of Inksurvey usage in Food Chemistry.

Some other tools such as PDF Annotator [16] and Ardesia [17] were used by UPV instructors to review and correct student coursework and assignments uploaded to the 
corresponding LMS. In the first case (Fig. 4), ink features were very helpful to make short comments on PDF documents, highlighting, or even adding drawings in order to better illustrate ideas. In case other formats or resources were delivered, a free digital sketchpad software called Ardesia was used to make colored free-hand annotations with digital ink everywhere, record it and return it to the student. According to White and Irons [18], these tools help faculty introduce some of the most useful types of formative feedback perceived by students and can therefore contribute to enhance their learning.

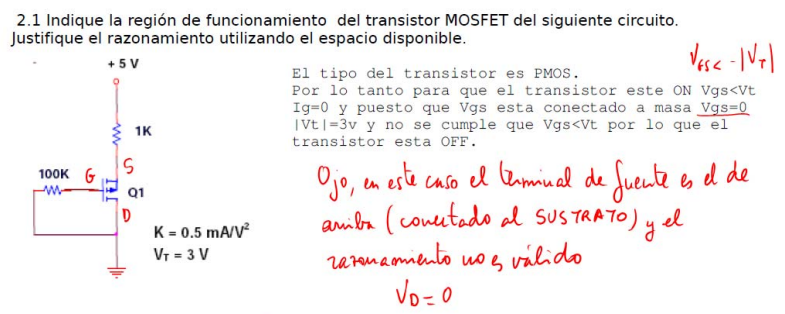

Fig. 4. Example of PDF Annotator usage in Computer Technology.

\section{RESULTS AND DISCUSSION}

To measure the effectiveness of the experiences, we report here some quantitative and qualitative measures of the effectiveness of the studied approach.

\section{A. Quantitative measures}

In order to assess the approach presented in this paper two groups have been selected in Computer Technology (TCO in the figures) as the experimental ones, while the remaining followed the "traditional" teaching approach. As there were nine morning groups and two afternoon groups at UPV, and their features use to be different, we selected two morning groups as the experimental ones (Tablet groups in Fig. 5 and 6 ) in order to facilitate the comparison.

We utilized three quantitative indicators to assess UPV experiences: the student activity score (lectures and labs), the written exam scores and the final score, which was computed as the arithmetic average of the first two. In fact, these indicators represent the average score in a 10-point scale for the different groups. It is important to point out that the second one is the more reliable as all the students take exactly the same exams regardless their group. However, the definition of student activity mark and accordingly the final score can be different depending on the studied groups.

Fig. 5 shows that students in the Tablet groups had better results in the three indicators when compared both to the morning groups and to all the groups, although the difference in the written exams was the lowest. Concerning the second academic year, Fig. 6 shows that although student activity is quite similar in the different groups, in particular when we compare Tablet and morning groups, once again students at experimental groups performed better in written exams compared to the rest of the groups. Similar results were obtained in terms of pass, fail, and dropout rates. Tablet groups obtained better results in the two considered academic years; however, the differences were small.

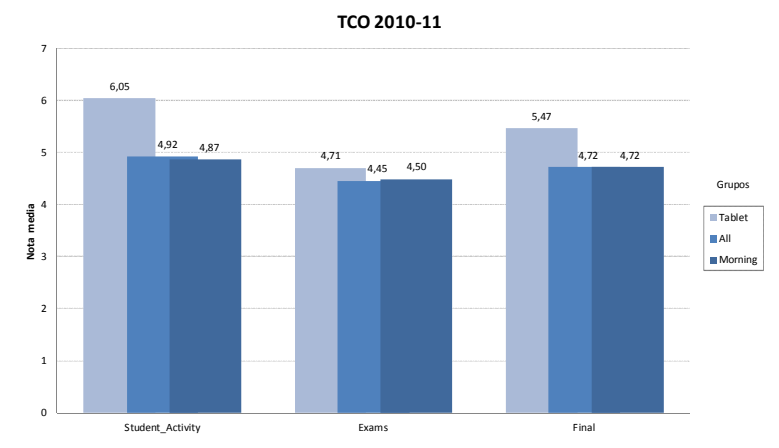

Fig. 5. Indicators for the academic year 2010-11.

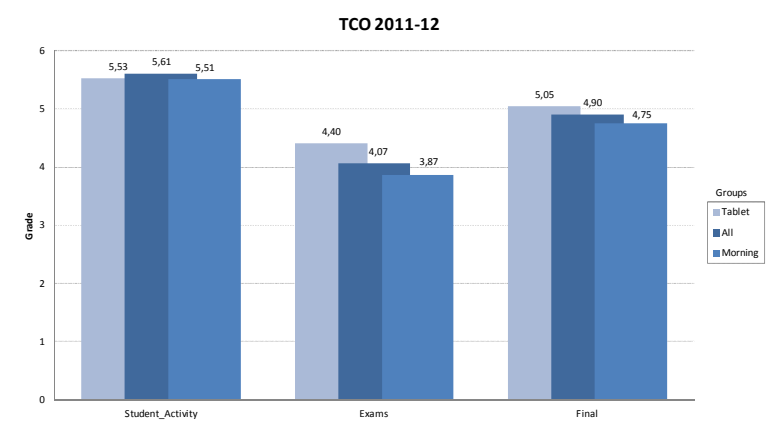

Fig. 6. Indicators for the academic year 2011-12.

Concerning UDLAP courses, in IA 332 (undergraduate) and IA 530 (graduate) were applied three quizzes, the courses were evaluated by obtaining scores of three quizzes, the third ones were part of the final exams. With the use of Tablet PCs and ink-enabled software (InkSurvey and Classroom Presenter) students improved their results in these summative assessments (final exam). In both cases, undergraduate and graduate courses, the formative assessment exercises performed with the Tablet PC and InkSurvey had a positive impact on the grades of the summative quizzes (Fig. 7).

Fig. 8 exhibits the mean scores (in a 10-point scale) of quizzes taken by undergraduate (IA332) and graduate (IA 530) students in the quizzes applied four years before implementing the use of the Tablet PCs (2005 to 2008) that were compared with results (after) obtained during the next four years (2009 to 2012) when the courses were redesigned and Tablet PC and associated technologies were utilized.

\section{B. Qualitative measures}

In order to examine how students perceived the use of Tablet PCs and associated technologies, at UDLAP we applied two online surveys to be answered by students (IA 332 and IA 530). The first survey was conducted at the beginning of the semester and the second one at the end. The first survey was related to the expectations of students in relation to the use of these technologies. The second survey was designed to assess the academic experience that students had with the use of 
these technologies. Both surveys have some open-ended questions.

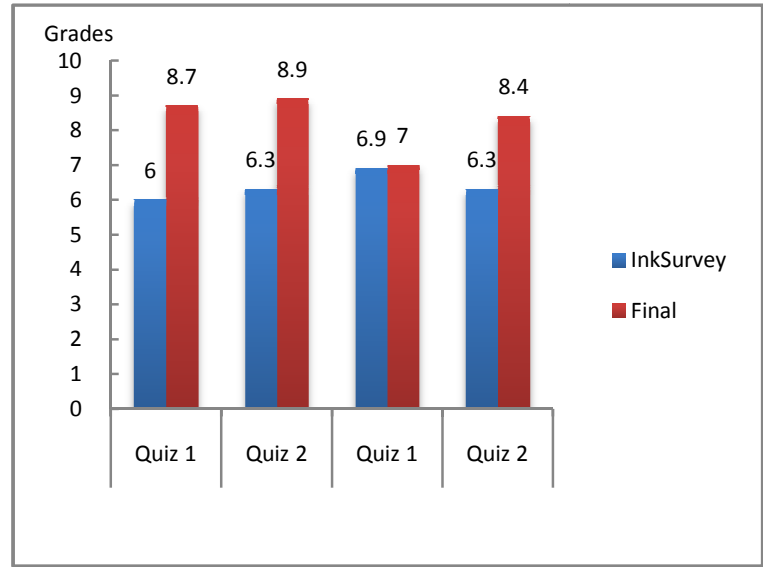

Fig. 7. Mean grades of undergraduate and graduate students in formative assessment (Inksurvey) and summative assessment (final) two first quizzes (years 2009-12).

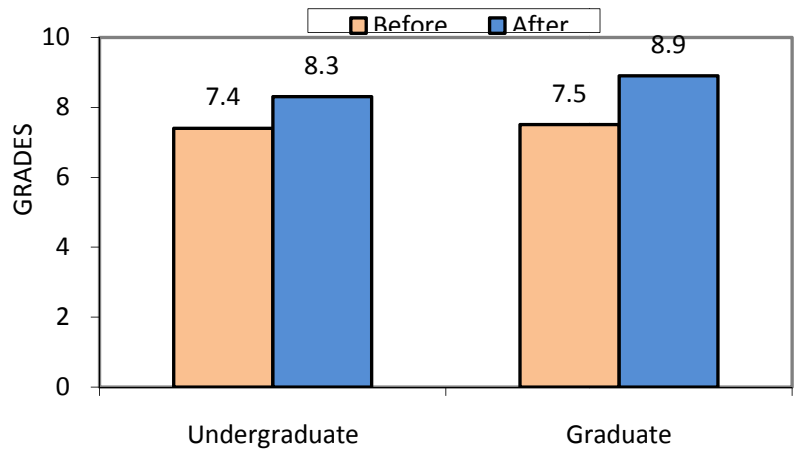

Fig. 8. Mean grades of quizzes taken by undergraduate and graduate students before (2005-08) and after (2009-12) course redesign and Tablet PC implementation.

$44 \%$ of students had previous contact with a Tablet PC before UDLAP studied courses. Students responses regarding the advantages of using a Tablet PC include: to write on it and take notes on the teacher's presentations, the ability to do graphics or drawings, write with the digital pen like in a notebook, the ability to interact with the teacher and peers to exchange information or ideas; the simplicity to take notes.

The second survey indicated that students' experience with Tablet PC and associated technologies was very interesting and different. They emphasized that it was a chance to take more didactic classes, or a course that was more dynamic, interactive and not boring. They also highlighted the experience of taking notes and writing on the teacher's presentations, which allowed them both to pay more attention to the class and interact with their teacher and classmates. Furthermore, the opportunity to send questions to the teacher and interact with him was highly appreciated.
In addition, UDLAP students underlined the increasing interaction with the teacher through more dynamic activities where they could draw pictures, graphs, solve problems, etc. They also stressed that more exercises and assessments in real time were conducted and the fact that they can participate and give opinions by using the capabilities of the Tablet PC.

Another result of the use of the Tablet PC was a visible increase in the motivation of students to participate in class discussions and problem solving activities. Also, redesigning courses improved understanding and ability of UDLAP students to solve practical food chemistry problems and complete real-world engineering projects, evaluated directly in several work products made by students, such as projects, problems, homework, tests and engineering journals.

Additionally, in order to carry out a qualitative analysis of the experience held at the UPV, each student participating in the experimental groups was asked to complete a common survey, few days before finishing the term. The first part of the questions asked the students to indicate how the Tablet PCbased approach influenced some key aspects of their learning process, such as class attendance, motivation, class work, or learning achievement. The survey also included some open questions concerning pros and cons, as well as suggestions.

Fig. 9 shows that most UPV students perceive a positive influence of Tablet PCs on class attendance, class work, motivation and learning achievement, while an important percentage considered Tablet PCs a source of distraction. It is also remarkable that most of them would recommend its usage in other courses.

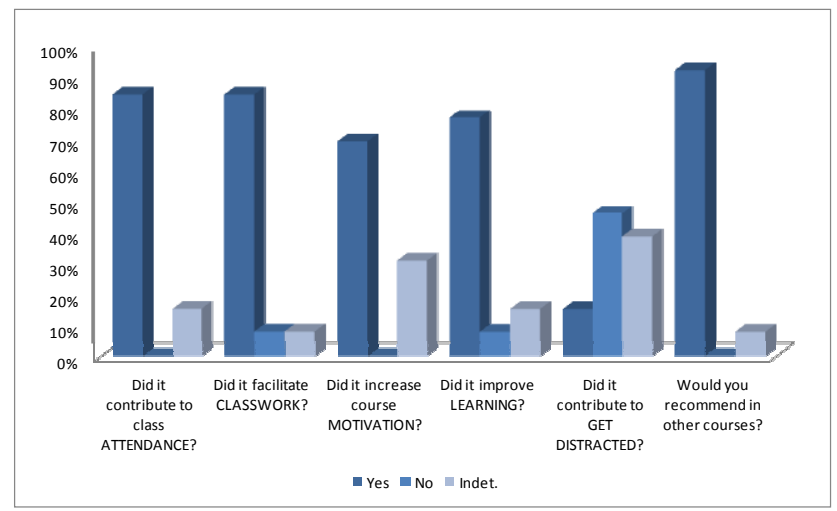

Fig. 9. UPV student post-questionnaire.

\section{CONCLUSIONS}

Thanks to the possibility to work in an anonymous way by Tablet PCs and associated digital ink technologies, students felt comfortable sharing their ideas with classmates, which enabled instructors to assess student understanding frequently during the process of instruction and problem solving. Formative assessments quickly identified the most common difficulties, allowed faculty to provide immediate feedback, redirect classroom activities, and/or refine instruction based on feedback received. Opportunities to make students' thinking visible were greatly enhanced, these gave them chances to revise their thinking, for "what if" thinking, as well as to help 
them reflect on their own processes as learners (to be metacognitive).

Students' initial conceptions provided the foundation on which more formal understanding of the subject matter was built. Further, frequent formative assessment helped make students' thinking visible to themselves, their peers, and their instructor. Facilitated by Tablet PC associated digital ink technologies, feedback (in studied courses) that guided modification/refinement in thinking increased.

Additionally, several other important impacts were achieved, particularly on instructor identifying the most common difficulties in UDLAP and UPV courses while providing immediate feedback of both written work products and oral presentations from students; helping students reflect on their own processes as learners; and instructor understanding of how through the use of Tablet PC associated technologies, student thinking can be revealed, and therefore the student learning experience in the classroom can be enhanced resulting in improvements in both instruction and student academic success.

\section{ACKNOWLEDGMENT}

We acknowledge financial support from HEWLETTPACKARD (HP), through the HP Technology for Teaching Higher Education Grant Initiative for Latin America for the project "High-Quality Learning Environments for Engineering Design: Using Tablet PCs and Guidelines from Research on How People Learn" as well as through the HP Catalyst Grant Initiative for the project "Critical Support Systems to Enhance the Development of 21st Century Expertise in Engineering Students: Using Tablet PCs and Associated Technologies, the Framework for 21st Century Learning, and Guidelines from Research on How People Learn". Similarly, UPV group received an HP Technology for Teaching High Education Grant Program for Europe, Middle East and Africa in 2008: "Improving effective learning in a first-year Computer Engineering course by using mobile Tablet PC technology".

\section{REFERENCES}

[1] L. Gazca, A. López-Malo, and E. Palou, "Analysis of the Implementation of the How People Learn Framework Through Direct Classroom Observation in Selected Food Engineering Courses," in Proc. ASEE Annu. Conf., Vancouver, BC, 2011.
[2] L. Gazca, E. Palou, A. López-Malo, and J. M. Garibay, "Capturing Differences of Engineering Design Learning Environments by Means of VaNTH Observation System," in Proc. ASEE Annu. Conf., Austin, TX, 2009.

[3] ANECA. (2005), Libro Blanco del título de Grado en Ingeniería Informática (in Spanish), [Online]. Available: http://libroblanco_jun05_informatica.pdf.

[4] J. V. Gutiérrez Cuba, A. López-Malo, and E. Palou, "Using Tablet PCs and Associated Technologies To Reveal Undergraduate and Graduate Student Thinking," in Proc. ASEE Annu. Conf., Vancouver, BC, 2011.

[5] F. Kowalski, S. Kowalski, and E. Hoover, "Using InkSurvey: A Free Web-Based Tool for Open-Ended Questioning to Promote Active Learning and Real-Time Formative Assessment of Tablet PC-Equipped Engineering Students," in Proc. ASEE Annu. Conf., Honolulu, HI, 2007.

[6] A. Enriquez, "Using Tablet PCs to Enhance Student Performance in an Introductory Circuits Course," in Proc. ASEE Annu. Conf., Louisville, KY, 2010.

[7] J. D. Bransford, A. L. Brown, and R. R. Cocking, How People Learn. Brain, Mind, Experience and School, expanded ed. Washington DC: National Academy Press, 2000.

[8] J. D. Bransford, N. Vye, and H. Bateman, "Creating High-Quality Learning Environments: Guidelines from Research on How People Learn," in "The Knowledge Economy and Postsecondary Education: Report of a Workshop," P. Albjerg Graham and N. G. Stacey, Eds. Washington DC: National Academy Press, 2002.

[9] E. Palou, L. Gazca, J. A. Díaz García, J. A. Rojas Lobato, L. G. Guerrero Ojeda et al., "High-Quality Learning Environments for Engineering Design: Using Tablet PCs and Guidelines from Research on How People Learn," International Journal of Food Studies, vol. 1, pp. 1$16,2012$.

[10] J.V. Gutiérrez Cuba, A. López-Malo, and E. Palou, "Graduate Student Perspectives on Using Tablet PCs and Associated Technologies, in Proc. ASEE Annu. Conf., San Antonio, TX, 2012

[11] Classroom Presenter website, Available: http://cs.washington.edu/education/dl/presenter.

[12] Classroom Assessment Techniques adapted from Angelo \& Cross (1993), Available: http://www2.creighton.edu/fileadmin/user/AEA/docs/CATs.pdf

[13] R. Anderson, R. Anderson, L. McDowell, and B. Simon, "Use of Classroom Presenter in Engineering Courses," in Proc. 35th ASEE/IEEE Frontiers in Education Conference, Indianapolis, IN, 2005.

[14] Vyew website, Available: http://vyew.com/s/

[15] InkSurvey website, Available: http://ticc.mines.edu/csm/inksurvey/

[16] PDF Annotator website, Available: http://www.grahlsoftware.com/en/pdfannotator/index.php

[17] Ardesia website, Available: https://code.google.com/p/ardesia/wiki/FAQ

[18] S. White, A. Irons, "How formative feedback enhances the student learning experience," in Proc. Frontiers in Education Conf. (FIE), Arlington, VA, 2010, pp. S1G-1,S1G-2. 